\title{
Contra el olvido: Todo lejos, de Alfons Cervera
}

\section{Against Forgetting: Alfons Cervera's Todo lejos}

\author{
Javier Sánchez Zapatero \\ Universidad de Salamanca, Departamento de Lengua Española \\ Área de Teoría de la Literatura y Literatura Comparada \\ zapa@usal.es
}

\begin{abstract}
Todo lejos (2015), the last novel by Alfons Cervera, recalls the arrest of a group of anti-Franco activists in the early seventies, a hardly known event in Spanish history that was probably silenced by political authorities. This paper will study the novel from a twofold perspective: on the one hand, the importance of memory. The novel has a choral structure of different voices that remember events that could potentially be identified with the author's autobiographical memories. On the other hand, the novel aims to report the atmosphere of terror created by Franco's dictatorship, the use of violence as a political weapon, and the accusation of dissidence suffered by many groups and individuals.
\end{abstract}

Keywords: Alfons Cervera, Todo lejos, Memory, Contemporary Spanish Literature

Todo lejos (Alfons Cervera, 2014) rememora un hecho acaecido a principios de la década de 1970, cuando un comando antifranquista, cercano al FRAP (Frente Revolucionario Antifascista y Patriota), fue detenido en la localidad levantina de Vilamarxant. A través de una estructura polifónica que da voz a los protagonistas y los testigos del incidente, se va reconstruyendo el suceso, subrayando la brutalidad con la que algunos fueron torturados y, sobre todo, el estigma que supuso para todos ellos haber sido marcados a ojos de la sociedad como desafectos al régimen. Entre el coro de voces narrativas aparece una que se identifica con la del propio autor y que va recapacitando sobre la historia que está relatando, provocando así que la obra adquiera una dimensión metaficcional que permite ver sus mecanismos de composición y un tono ensayístico con el que se reflexiona, a través de diversos excursos, 
sobre la gestión de la memoria y la influencia de la dictadura franquista en la España contemporánea.

La historia se presenta ante al lector como el resultado de una investigación, intercalando los testimonios de once personajes involucrados en el suceso con los del propio narrador, responsable de obtenerlos y transcribirlos, empleando para ello el habitual estilo de Cervera, caracterizado por la asepsia, el uso de la frase corta y la ausencia de puntos y aparte. De este modo, la obra podría encuadrarse en la variante de "novelas de investigación regresiva" que Martínez Rubio (2016, p. 176) ha identificado dentro de la literatura de la memoria, caracterizada por configurarse en torno a tres planos: el de la historia - constituido por el hecho histórico cuyas características se intentan desvelar y representado en este caso con la detención-, el de la acción - el propio de la investigación que se desarrolla desde el presente, y que se correspondería con la labor documental de Cervera, que le lleva a localizar a los protagonistas del suceso y a entrevistarse con ellos - y el del discurso - surgido como consecuencia del anterior y, en consecuencia, identificado con el contenido y la forma que terminan por quedar fijados en la obra literaria-. En palabras de Martínez Rubio (2016, pp. 175-176), en la investigación regresiva, y por ello en Todo lejos, "todo ha ocurrido ya: el caso investigado y la propia investigación [...]: escribir [sirve] para ordenar y para dar sentido a lo que ocurrió y, sobre todo, a por qué el narrador se interesó por la historia".

Los protagonistas de las entrevistas a quienes se da voz son ocho activistas —Juan, Andrés, Luis, Pedro, Berto, Nino, Daniel y Sebas—; uno de los guardias civiles que participó en la detención — Ramírez-; un testigo que habitaba en la misma población en la que tuvieron lugar los hechos - Ginio, cantante del grupo de música Los Taburos-; y la hija de uno de los represaliados - María, hija de Luis, que aún no había nacido en la época que se rememora-. Gracias al relato de sus experiencias, en el que se entremezclan los recuerdos de lo sucedido con su visión de la actualidad, se van reconstruyendo los hechos. Esta estructura de mosaico, que no respeta la linealidad temporal ni la ilación entre los diversos acontecimientos narrados, provoca que la obra tenga "algo de rompecabezas, de relato policíaco, con un narrador que actúa a la manera de un detective, al indagar, recomponer y darle sentido a unos hechos olvidados por la mayoría" (Valls, 2014, en línea) y que obligue a una lectura activa capaz de relacionar y ordenar de forma coherente los diferentes testimonios para poder obtener una visión de conjunto de lo sucedido. En novelas anteriores del autor se pueden detectar análogas técnicas, tal y como ha explicado Georges Tyras (2013, p. 15), quien ha señalado como una de las características básicas de la literatura de Cervera es el uso de un procedimiento que provoca que "las secuencias resulten yuxtapuestas, no según una concatenación narrativa que sería fruto de la continuidad o de la causalidad, sino según el orden aleatorio de la rememoración, factor de la discontinuidad de la representación". 
Fruto de una decisión programática, esta forma de composición está en plena consonancia con algunos de los sustentos formales e ideológicos de Todo lejos. Por un lado, demuestra su relación con la memoria: "lo que hay que hacer es respetar los flujos inestables de la memoria, la selección de lo que se recuerda, el ir y venir de los sofocos asfixiantes que provoca el miedo" (Cervera, 2014, p. 22), señala el narrador, evidenciando con ello que los recuerdos son vagos, imprecisos y desordenados, como muchos de los testimonios que conforman la obra. Por otro, pone de manifiesto su voluntad de oponerse a las verdades oficiales y únicas de la historia: "se acabaron ya las voces omniscientes, las que lo dicen todo [...], se acabaron, con esas voces, los ojos que abarcaban el paisaje en que transcurre la historia, todo el paisaje, sencillamente porque los dioses no existen" (Cervera, 2014, p. 22), afirma más adelante, imbricando así su literatura con la tradición posmoderna que huye de las visiones únicas y desafía los conceptos clásicos de verdad. No en vano, para Valeria Possi (2015, p. 132), "la multiplicación de las voces narrativas y la fragmentariedad de la narración [...] simbolizan precisamente la irreprimible pluralidad que se necesita a la hora de oponer unas memorias privadas a los discursos oficiales de los dominantes vigentes hasta hace tan poco tiempo".

La novela narra la detención de un grupo de resistencia clandestina cuyas principales acciones consistieron en imprimir pasquines con consignas revolucionarias y llevar a cabo algunos destrozos en el mobiliario urbano, como los que pretendían hacer cuando fueron detenidos al ser sorprendidos con unos botes de pintura con los que iban a escribir algunas consignas políticas en un edificio del pueblo. Ahora bien, trascendiendo el mero relato de su apresamiento, la historia se ocupa de la brutal tortura que sufrieron Juan y Andrés, del trauma que supuso entre los miembros del grupo el suicidio de Martín — quien decidió quitarse la vida al saber de la detención de sus compañeros y de la consiguiente inminencia con la que las autoridades iban a acudir en su búsqueda - y de la forma en la que fueron señalados en el pequeño y opresivo microcosmos de un pueblo del interior levantino. Paradigmático ejemplo de los procesos de la "memoria manipulada" (Ricœur, 2004) que surgieron en sociedades totalitarias como el franquismo al convertir en enemigos del pueblo a quienes intentaron luchar por su libertad, el proceso por el que la actividad de los integrantes del grupo clandestino fue desideologizada y presentada como simple delincuencia se manifiesta de forma recurrente a lo largo de la obra. Así, por ejemplo, se relata cómo la madre de Berto le preguntaba insistentemente "en qué líos andaba metido" (Cervera, 2014, p. 19) —evidenciando con ello la reducción de la actividad de resistencia política a la de "barullo, gresca y desorden", según la tercera acepción del término en el diccionario de la RAE_-; cómo a la hija de Luis le dicen, varias décadas después de lo sucedido, que su padre "fue terrorista" (Cervera, 2014, p. 20); cómo Ginio, al evocarlos, defiende que eran "gente normal" (Cervera, 2014, p. 76) a pesar de la demonización a la que fueron sometidos - "de repente ya no eran unos 
chavales el pueblo sino unos delincuentes" (Cervera, 2014, p. 153)—; o como Ramírez, el guardia civil, llega a decir, a propósito de la tortura, que "no todo el que recibía aquellas hostias era inocente" (Cervera, 2014, p. 158).

Semejante proceso de degradación provocó que todos los miembros del grupo tuvieran que iniciar una nueva vida al salir de la cárcel, obligados a elegir entre desplazarse y comenzar de cero en otro lugar — "no íbamos a tener una vida fácil [...] [y] mis hijos no podían cargar con ese peso", dice Pedro para justificar su traslado a Francia; "somos de aquel lugar donde el olvido te sirve para no convertirse en basura, y después de aquellos días eso es lo que había para nosotros por todas partes: basura" (Cervera, 2014, p. 85), señala Lino para justificar su decisión de irse a vivir a la provincia de Alicante a trabajar como profesor y no regresar hasta décadas después - o permanecer en el pueblo sometidos a la mirada prejuiciosa de unos paisanos que no volvieron a tratarles como antes. Tal y como señala Ginio, a los encarcelados "todo el pueblo los conocía, y luego les dieron la espalda, les negaron todo porque en aquel tiempo era difícil estar en el lado que ellos defendían" (Cervera, 2014, p. 152). Juan, uno de los que sufrió la brutalidad de la tortura, quedando marcado incluso físicamente a ojos de la sociedad con una cara "que parecía un revoltijo de carne machada" (Cervera, 2014, p. 43), expone en uno de sus testimonios la situación:

Nadie quiso saber nada de lo que sucedió aquellos días, de por qué estábamos donde estábamos la noche de las detenciones y en los días siguientes, cuando caímos los demás. Nadie quiso saber nada de las torturas, de la impunidad que siempre tuvieron la policía y la guardia Civil. Lo que sí sabían era cargarnos a nosotros la muerte de Martín. Eso sí que lo hicieron bien. Para escapar de esa carga, yo decidí borrarlo de la memoria. No podemos estar a todas horas con el dolor de tanto daño encima y de tanta culpa metida en las tripas como una rata muerta de hambre. [...] Sé que un día los guardias se ensañaron conmigo, claro que lo sé. Pero no quiero recordarlo. Porque si lo recordara sería como darles la razón a aquellos hijos de puta. Porque cada vez que me vinieran a la cabeza los golpes, los insultos, esa persistente humillación que nunca abandona a quienes sufren la derrota. (Cervera, 2014, p. 78)

De esta forma, el olvido se presenta de forma dual, puesto que, si por un lado aparece como la reacción temerosa de una sociedad sometida a las imposiciones de un régimen que condenó al silencio y al ostracismo cualquier actividad disidente - como señala Andrés, "después del miedo lo que llega es el olvido" (Cervera, 2014, p. 103) - , por otro es uno de los procedimientos a través del que las víctimas logran pasar página, liberarse del trauma y seguir adelante con sus vidas. Al sacar a la luz la historia de la detención y dotar a sus protagonistas de la humanidad de la que el régimen franquista les privó al relegarles a la categoría de meros delincuentes, Todo lejos parece haber nacido con la vocación de "combatir el absentismo de la memoria" (Obiol, 2015, en línea). Se confirma así que su relación con la memoria 
no solo reside en el hecho de nacer de los recuerdos de los protagonistas del incidente narrado, sino también y sobre todo en su capacidad para "hacer recordar", dotándose de un valor cognitivo y pragmático que le lleva a transmitir a los demás lo acontecido para evitar que caiga en el limbo del olvido, rehabilitando la dignidad de aquellos a quienes casi todo les fue negado.

El hecho relatado en Todo lejos es real, y así lo atestigua tanto la forma, que reproduce una estructura documental, como diversos elementos paratextuales de la novela, desde el preámbulo - "estas páginas cuentan una historia real" (Cervera, 2014, p. 7) - hasta las notas finales, en las que se señalan las fechas en las que el autor realizó las entrevistas que hizo para documentarse del suceso, se incluye una fotografía en la que aparece uno de los testigos a quienes se da voz, se anexan unos breves textos en los que se narra cómo evolucionaron las vidas de los personajes después del incidente y se indica una referencia a un vínculo en la Red en el que aparece un vídeo con una actuación del grupo musical Los Taburos, a cuyos conciertos acudían frecuentemente los protagonistas. Asimismo, Cervera ha insistido en el carácter histórico de los hechos narrados en diversas entrevistas y apariciones públicas:

Lo que cuento es real y sucedió en Vilamarxant, el pueblo donde yo vivía entonces, en julio de 1971. Yo quería contar esa historia de jóvenes revolucionarios, quería devolverles una dignidad y una nobleza que las circunstancias de la época les negaron. (Cervera, cit. por García, 2014, p. 72)

Sin embargo, Todo lejos no es, ni pretende ser, un ensayo, ni un testimonio, ni un estudio histórico, ya que "parte de hechos reales, pero se vale de los mecanismos de la ficción para reconstruirlos y darles forma de relato" (Valls, 2014, en línea). Tal y como señala la voz narrativa que se identifica con el autor, "la ficción manda" (Cervera, 2014, p. 23). De ahí que la exactitud que se demanda a los textos referenciales no aparezca en la obra, que intenta contar la historia de los antifranquistas "con el único animo de no traicionarla, [...] [a pesar de que] la novela inventa" (Cervera, 2014, p. 22). Lejos de perseguir una verdad empírica, lo que se busca es transmitir la "verdad esencial" de lo sucedido, más fundamentada en la voluntad de Cervera de ser sincero y respetuoso con los hechos, expuestos sin ningún afán deformador o manipulador, que en la absoluta objetividad. El propio autor llegó a señalar que "la mejor manera de contar una historia real era hacerlo desde la ficción, para $[\ldots]$ jugar con argumento y personajes que la exactitud de la historia que negaba" (Cervera, cit. por García, 2014, p. 72), coincidiendo así con la postura de, entre otros, Jorge Semprún (2002, p. 141), para quien "la verdad esencial de la experiencia [...] solo es transmitible mediante la escritura literaria". ${ }^{1}$ Por tanto, Todo

\footnotetext{
${ }^{1}$ No es causal que en el epílogo de Todo lejos aparezca una muy representativa cita de Semprún, tomada de Adiós, luz de veranos (1998): "las novelas no son la vida auténtica: son mucho más" (Cervera, 2014, p. 173).
} 
lejos genera un contrato lector al que Manuel Alberca (2007, pp. 61-62) se ha referido como "pacto ambiguo" y que, a medio camino entre la ficción y la referencialidad, provoca una recepción "que mantiene una relación con respecto a lo real y a lo vivido, pero [a la que] los autores, al proponer el estatuto de ficción, le confieren un carácter textual". Así, pierde su concreción y amplía el valor de lo relatado hasta adquirir una dimensión universal y ejemplar que le lleva a no referirse solo al hecho puntual que ocurrió en el verano de 1971 en Vilamarxant, sino a todos los actos de barbarie y represión que llevó a cabo el franquismo, y por extensión cualquier régimen totalitario, como se reconoce en el propio texto, en el que el narrador afirma que "la memoria ha de ser justa, ejemplar" (Cervera, 2014, p. 140). Durante la dictadura hubo muchos sucesos análogos a los que relata Todo lejos, muchos jóvenes golpeados en comisarías, muchas personas cuya reputación fue destruida tras una detención, muchas víctimas de la injusticia... y todos están presentes en la obra gracias al poder de la ficción como epifanía de lo real. Tal y como ha señalado Fernando Valls (2014, en línea), la novela se lee como una ficción, pero también "como una historia real y posible".

La ambigüedad de la recepción que genera Todo lejos es corroborada por la utilización como trasunto del espacio real en que ocurrió lo relatado del escenario de Los Yesares, al igual que en el ciclo de novelas que conforman "Las voces fugitivas", al que el autor se ha referido en alguna ocasión como el "ciclo de la memoria", integrado por El color del crepúsculo (1995), Maquis (1997), La noche inmóvil (1999), La sombra del cielo (2002) y Aquel invierno (2005). El hecho de que en las anteriores obras sirviera para referirse a Gestalgar, su localidad natal, y en este caso a Vilamarxant, donde residió algunos años durante su juventud, pone de manifiesto la condición de geografía personal de Los Yesares, que permite al escritor adentrarse en los vericuetos de su memoria y, de forma especial, en las experiencias de la represión franquista que fue conociendo durante su niñez y juventud. No en vano, parece existir una vinculación afectiva e ideológica entre Cervera y las historias narradas en sus novelas, como se puede observar en Todo lejos al comprobar que el autor se presentó en muchas de las entrevistas que acompañaron la promoción del libro como amigo de los activistas detenidos y confesó que uno de los objetivos de su obra era mantener vivo el recuerdo de aquellos que quisieron derribar la dictadura (Cervera, cit. por García, 2014, p. 72). La relación entre el escritor y la historia relatada se intensifica también gracias a la mención de la educación sentimental y cultural de su generación, expresada a través de diversos fogonazos sensoriales con los que se reconstruye la imagen y el sonido de la época: canciones de música pop - hay alusiones a The Beatles, The Animals o Los Relámpagos, entre otros-, el cine de la nouvelle vague de Jean-Luc Godard, las salas de baile, el Renault Gordini... Según Teresa Fraile (2014, p. 109), el uso de este tipo de referencias en las narraciones tendría una doble voluntad nostálgica, ya que "por un lado se recurre a ellas apelando al recuerdo personal, biográfico, individual, y por otro 
[...] enlazan con la nostalgia colectiva, aludida previamente, por la que la sociedad de un presente elabora recuerdos ficticios de un pasado". Además de para recrear el tiempo y el espacio diegéticos de la historia, y la relación de Cervera con ellos, su presencia sirve para calibrar el impacto que tuvo la detención, con la que se puso fin a la inocencia de los protagonistas, que pasaron de bailar en una terraza las canciones de las bandas locales y soñar con que era posible cambiar el mundo a sufrir en sus propias carnes toda la brutalidad del régimen. Por eso la obra puede ser leída también, en cierto modo, como una novela de formación que va mostrando el cambio de unos personajes que pasaron bruscamente del idealismo a la realidad.

El uso recurrente de Los Yesares no es la única conexión entre las diversas obras de Cervera, que también permanecen vinculadas por la voluntad del autor de ceder el protagonismo a los marginados de la historia, a aquellos a los que el discurso dominante les privó de voz y de presencia. No es baladí que el autor haya pasado de ocuparse en sus primeras novelas de los maquis que intentaron luchar contra el régimen en los años de inmediata posguerra, cuya presencia fue especialmente destacada en la serranía del interior de Valencia en la que se sitúa Los Yesares, a hacerlo de los activistas que mantuvieron viva la llama de la resistencia mientras la dictadura agonizaba. Más que caracterizar a unos y otros como enemigos del franquismo, los textos de Cervera inciden en su condición de represaliados que sufrieron la violencia del poder y la indiferencia, cuando no el desprecio, de buena parte de la sociedad, así como en su imbricación en un colectivo que necesita de la acción de la memoria para poder ser rescatado del olvido. De hecho, el propio autor ha explicado que su literatura "ha resucitado a toda esa gente que llevaba en el olvido tantos años, y ya se sabe que el olvido es algo que se parece mucho a la muerte" (Cervera, cit. por Tyras, 2008, p. 212). Son las suyas, en definitiva, narraciones que pretenden "la recreación de un mundo que, a fuerza de silencios, se iba perdiendo irremediablemente en el rodar implacable de los relojes y la inmisericorde desaparición de las generaciones" (Soldevila, 2013, p. 13).

Aunque parte de un proceso de documentación que se muestra de forma explícita ante el lector, la recreación de ese mundo pasado, y de los acontecimientos que en él tuvieron lugar, no se hace desde la reconstitución objetiva y exacta. No hay en las novelas de Cervera descripciones minuciosas, sino que el espacio y el tiempo se va configurando a través de sensaciones y referencias que dotan a la historia de la concreción que su relación con el tiempo histórico exige. De todas ellas, quizá la más significativa sea el miedo, presente en todo el ciclo de "Las voces fugitivas" -y en especial en Maquis, cuya primera frase es "yo sé mucho del miedo" (Cervera, 2013, p. 149)—, que aparece en Todo lejos a través de la reacción que lleva a Martín a suicidarse para no ser detenido, de la inquietud con la que Andrés escucha los golpes propinados a Juan en la celda contigua, del rechazo con que los habitantes reciben a los detenidos tras su liberación, etc. Su presencia no solo sirve para explicar, y en cierto modo justificar, la actitud de buena parte de la ciudadanía 
durante el franquismo $-\mathrm{y}$ al mismo tiempo, para reivindicar la labor de quienes, como los protagonistas, decidieron embarcarse en procesos de lucha clandestina-, sino también para mostrar que la dictadura fue, por encima de todo, un régimen de terror en el que "el sometimiento de los enemigos tenía un claro propósito de venganza, pero la coacción, observada desde otra perspectiva, servía sobre todo para disuadir a los potenciales disidentes de adoptar actitudes contestatarias" (Molinero, 2006, p. 231). Resulta significativo que Todo lejos sitúe ese miedo a principios de la década de 1970 y no en la inmediata posguerra, como es habitual en cierta narrativa española reciente, ${ }^{2}$ pues así se intentan desmontar algunos de los tópicos que más recurrencia se manejan sobre la época, vinculados al desarrollismo y a la pretendencia liberalización de una dictadura a la que el paso del tiempo no restó ni un ápice de su capacidad represora. ${ }^{3}$

El hecho de que la reconstrucción del tiempo pasado no se haga buscando el detalle y la más absoluta rigurosidad ha llevado a Tyras $(2008$, p. 109) a señalar que la producción narrativa de Cervera ha de situarse en los territorios de la "novela de la memoria, en la que los datos y acontecimientos importan menos que la huella que han dejado y el eco que todavía producen en la vida personal, social e íntima de los personajes". De ahí que en Todo lejos adquiera tanta importancia el presente, reflejado en los testimonios de unos personajes que no se limitan a rememorar, sino que incluyen con cierta recurrencia en sus parlamentos referencias a su vida actual y a su forma de ver el mundo contemporáneo. Son constantes las alusiones "al desencanto por la evolución política de algunos dirigentes izquierdistas de entonces" o la interpretación de la Transición como "una traición a aquellos que arriesgaron su vida para acabar con el régimen" (Valls, 2014, en línea). El personaje de Pedro, por ejemplo, llega a señalar que "los mayores torturadores cuando la dictadura ocuparon los altos cargos en la política al llegar la democracia, y ahí se mantuvieron, incluso ascendieron a lo más alto durante los años socialistas de Felipe González" (Cervera, 2014, p. 165), citando incluso de forma explícita los nombres de Roberto Conesa, Manuel Ballesteros o Antonio González Pacheco "Billy el Niño", destacados miembros de la Brigada Político-Social encargada de reprimir los movimientos anti-

\footnotetext{
${ }^{2}$ Sin ánimo de exhaustividad, piénsese en ejemplos como La noche de los cuatro caminos (Andrés Trapiello, 2001), La voz dormida (Dulce Chacón, 2002), Los girasoles ciegos (Alberto Méndez, 2004), la serie "Episodios de una guerra interminable" (Almudena Grandes, 2010-2015), Las trece rosas (Jesús Ferrero, 2011), Donde nadie te encuentre (Alicia Giménez Bartlett, 2011), Si a los tres años no he vuelto (Ana R. Cañil, 2011) e incluso algunas de las anteriores novelas del propio Cervera.

${ }^{3}$ En ese sentido, son varias las concomitancias que la novela de Cervera mantiene con El vano ayer (Isaac Rosa, 2004), que, a través de una historia que tiene lugar durante las más intensas fases de agitación universitaria de la década de 1960, intenta resquebrajar la memoria hegemónica impuesta desde el poder, denunciar la brutalidad con la que se emplearon las fuerzas policiales durante toda la dictadura y criticar el costumbrismo nostálgico con el que algunos productos culturales contemporáneos rememoran el franquismo.
} 
franquistas, que, a pesar de ser conocidos por las palizas y los malos tratos que acostumbraban a infligir a los detenidos, continuaron ocupando cargos de poder en la estructura policial del Estado después de la llegada de la democracia. Lino, por su parte, se queja de que "murió Franco y lo que vino luego fue un barullo vergonzoso de siglas e intereses" (Cervera, 2014, p. 87) más preocupados por llegar al poder que por hacer justicia y reparar el daño hecho por el régimen.

Esta meditación sobre el presente se presenta como la lógica consecuencia de la rememoración, ya que "el pasado no es nada si no nos ayuda a entender mejor lo que nos pasa" (Cervera, 2014, p. 140). La conexión entre lo que fuimos -o lo que fueron - y lo que somos —o lo que serán- está presente de forma constante en toda la producción literaria del autor, que siempre ha mostrado su interés por "el tiempo y el espacio en los relatos que cuentan no lo de ayer sino lo que sucede ahora mismo" (Cervera, 2014, p. 140) y, en consecuencia, por la articulación de un uso ejemplar de la memoria que, tal y como demandaba Todorov (2000), al que se cita explícitamente en Todo lejos, permita articular para el pasado un significado global que, más de allá de la concreción histórica, tuviera validez en el presente.

Junto a la propia estructura narrativa, que pone de manifiesto la vinculación entre las dos dimensiones temporales al basarse en una retrospección que intenta aclarar desde el presente algo acaecido décadas atrás, adquiere gran relevancia en la actualización del pasado el personaje de María. Frente a la actitud pasiva e incluso resignada de los miembros del comando, ${ }^{4}$ la hija de Juan adopta una postura mucho más vehemente. Así, se rebela contra una sociedad en la que "nadie quiere acordarse de nada" (Cervera, 2014, p. 70) y en la que se habla mucho de la Guerra Civil, pero no parece querer recordarse la dictadura, como si los más de treinta años de terror no fueran más que un hiato en la historia de España de los que nadie se quiere ocupar. $\mathrm{Su}$ presencia en la obra, junto a del propio narrador en cuya voz e ideología puede detectarse la presencia de Cervera, situaría a esta como ejemplo de lo que Sebastiaan Faber (2011) ha denominado como "acto afiliativo", basado en el imperativo moral de investigar y denunciar la violencia a la que fueron sometidas. Es decir, lo que importa de María no es tanto su condición de hija de un represaliado - lo que situaría su testimonio en el ámbito de la "postmemoria" (Hirsch, 2008), término con el que se denomina a los relatos de quienes rememoran unas vivencias traumáticas que les fueron transmitidas por sus mayores pero ellos jamás llegaron a experimentar-,

\footnotetext{
${ }^{4}$ Grosso modo, sus posturas oscilan entre el olvido lo sucedido para poder seguir viviendo; la evocación con orgullo, convencidos de haber sido fieles a su ideario y de no haberse resignado a pesar de la futilidad de la lucha contra un régimen cuyo líder terminó muriendo en la cama - "quiero pensar que sí, que todo no fue inútil" (Cervera, 2014, p. 70), confiesa Sebas; "ahí estábamos, intentando romper el equilibro de una dictadura" (Cervera, 2014, p. 109), recuerda Luis-; y el mero lamento por el desconocimiento de la sociedad - "Martín no sale en google, ni en ningún sitio" (Cervera, 2014, p. 162), dice Lino, quejándose con amargura de que nadie recuerde a una víctima que prefirió quitarse la vida a soportar la represión franquista.
} 
sino, sobre todo, su afiliación simbólica e ideológica al colectivo de víctimas del franquismo y su actitud comprometida al servicio del desvelamiento de los procesos represivos llevados a cabo durante la dictadura. De esta forma, Todo lejos proyecta una dimensión performativa, coincidente con la desarrollada por el autor a lo largo de toda su dilatada trayectoria, que le lleva a trascender lo meramente estético para hacer de su literatura un acto de compromiso con los derrotados, las víctimas y los parias de la historia. Por eso Bonvalot (2013) ha utilizado términos como "resistencia" o "disidencia" para referirse a su literatura, de la que Tyras (2013, p. 19) ha señalado que "se levanta con el firme propósito de una reivindicación ética y empática del mundo de los perdedores desde la autenticidad más acendrada" y Possi $(2015$, p. 122) ha afirmado que "se propone como un medio apto para subvertir las narraciones dominantes a través de contrahistorias en las que se vuelve a otorgar el derecho de palabra a las clases subalternas o a las víctimas".

Esta labor de restitución resulta sumamente relevante si se tiene en cuenta que el desconocimiento de sucesos como el acontecido en Vilamarxant se ha venido prolongando hasta una actualidad en la que cada vez son más frecuentes voces como las que representa el guardia civil Ramírez, para quien "lo que pasó aquellos días ya no interesa a nadie" (Cervera, 2014, p. 44), "el pasado no es más que «las tonterías de antes»" (Cervera, 2014, p. 121) y "si nos ponemos a contar lo de antes seguro que volveremos a jodernos los unos a los otros, como pasó en la guerra" (Cervera, 2014, p. 120). Es quizá este personaje el que de forma más paradigmática singularice la voluntad de ignorar —olvidando lo sabido o no mostrando interés alguno en sabery no juzgar lo acontecido durante el franquismo, a través tanto de la recurrencia con la que sus parlamentos incluyen expresiones como "no lo sé", "no me consta" o "no me acuerdo", fórmulas retóricas voluntariamente ambiguas que en ningún caso niegan que lo sucedido fuera verdad, como de la "banalidad del mal" (Arendt, 2008) que muestra la continua justificación de sus actos aludiendo a su imbricación en un sistema jerárquico: "solo cumplí con mi deber todo el tiempo que fui miembro del cuerpo" (Cervera, 2014, p. 82).

Frente a actitudes como esas y a la convicción, frecuentemente manifestada en el discurso de ciertos sectores de la política y la sociedad españolas, de que hay que pasar página, olvidar lo sucedido, mirar hacia delante como si nada hubiera ocurrido y no restituir a quien fue humillado durante el franquismo porque eso supondría generar nuevos enfrentamientos, se oponen obras como Todo lejos, sintomáticos ejemplos de que no hay presente sin memoria y no hay memoria sin verdad. 


\section{BIBLIOGRAFÍA}

Alberca, M. (2007). El pacto ambiguo. De la novela autobiográfica a la autoficción. Madrid: Biblioteca Nueva.

Arendt, H. (2008). Eichmann en Jerusalén. Barcelona. Debolsillo.

Bonvalot, A. L. (2013). "Los caminos de la disidencia: Alfons Cervera e Isaac Rosa". En M. T. Navarrete Navarrete \& M. Soler Gallo (Eds.), Ay iqué triste es toda la humanidad! Literatura, cultura y sociedad española contemporánea (pp. 321-330). Roma: Aracne.

Cervera, A. (2013). Las voces fugitivas [incluye El color del crepúsculo, Maquis, La noche inmóvil, La sombra del cielo y Aquel invierno]. Barcelona: Piel de Zapa.

- (2014). Todo lejos. Barcelona: Piel de Zapa.

Faber, S. (2011). "La literatura como acto afiliativo: la nueva novela de la Guerra Civil (2000-2007)". En M. P. Álvarez Blanco \& A. Dorca (Eds.), Contornos de la narrativa española actual (2000-2010): un diálogo entre creadores y críticos (pp. 101-110). Madrid-Frankfurt: Iberoamericana-Vervuet.

Fraile, T. (2014). "Nostalgia, revival y músicas populares". Quaderns, 9, 107-114.

García, A. (2014, 28 octubre). "Alfons Cervera: «Todo es hablar de la guerra y de la dictadura no habla nadie»". Levante. El Mercantil valenciano, 72.

Hirsch, M. (2008). "The Generation of Postmemory”. Poetics Today, 29, 103-128.

Martínez Rubio, J. (2016). Las formas de la verdad. Investigación, docuficción y memoria en la novela hispánica. Barcelona: Anthropos.

Molinero, C. (2006). ¿Memoria de la represión o memoria del franquismo? En S. Juliá (Ed.), Memoria de la guerra y del franquismo (pp. 216-246). Madrid: Taurus.

Obiol, M. J. (2015, 20 marzo). "Un pedazo de tiempo". El País. Recogido en: http://cultura.elpais. com/cultura/2015/03/18/babelia/1426695935_248633.html

Possi, V. (2015). "El pluralismo en la narrativa actual: Alfons Cervera y sus voces fugitivas". Confluenze: Rivista di Studi Iberoamericani, 7 (2), 120-133.

Ricœur, P. (2004). La memoria, la historia, el olvido. México D. F.: Fondo de Cultura Económica.

Semprún, J. (2002). La escritura o la vida. Barcelona: Tusquets.

Soldevila, I. (2013). "Salvar la memoria". Quimera, 156, 63-65.

Todorov, T. (2000). Los abusos de la memoria. Barcelona: Seix Barral.

Tyras, G. (2008). Memoria y resistencia. El maquis literario de Alfons Cervera. Barcelona: Montesinos.

- (2013). "Alfons Cervera: hacia una poética de las voces". En A. Cervera, Las voces fugitivas (pp. 13-19). Barcelona: Piel de Zapa.

Valls, F. (2014, 16 diciembre). "Sobre Todo lejos, de Alfons Cervera”. La nave de los locos (Página personal). Recogido en: http://nalocos.blogspot.com.es/2014/12/sobre-todo-lejos-de-alfons-cervera.html (1 septiembre 2016). 